\title{
Simulation and Research of Driving Motor Speed Control System for Electric Vehicle
}

\author{
Jiandong Guo ${ }^{1}$, Longlong Song ${ }^{2}$ and Pei Zheng ${ }^{2}$ \\ ${ }^{1}$ Hohhot Vocational College, Hohhot, China \\ ${ }^{2}$ College of Energy and Power Engineering, Inner Mongolia University of Technology, Hohhot, China
}

\begin{abstract}
In this paper, a mathematical modeling is set up based on the trigger equipment of light electric vehicle speed control system, and the unit step response curve of dual closed-loop speed control system is given by using the simulation software simulink. A conclusion can be drew that the unit step response quality index of dual closed-loop speed control system is generally good, but the maximum overshoot of this system is relatively large. Considering overall stability, this system should be adjusted. On the basis of these, a double closed-loop speed control system design plan is proposed with rotating speed differential negative feedback, and a rotating speed of negative feedback link is introduced in this system. The simulation results show that the maximum overshoot of this system is reduced by $32.37 \%$, and the overall data shows that this system has excellent stability performance, and also the response speed of this system is guaranteed.
\end{abstract}

Keywords-DC motor; simulink; speed regulating system; negative feedback

\section{INTRODUCTION}

Considering the limited petroleum resources and the current environmental pollution, the electric vehicle has many advantages, such as zero pollution, low noise, widely energy sources and so on. Because of the car is frequent started and braked during driving, so it is essential for election vehicle to research the drive motor system.

DC has experienced the development speed, changing the armature voltage speed, changing the magnetic speed control and PWM DC motor speed. Later, entered the phase of double closed-loop DC speed [1].

Paper [2] based on the electric vehicle driving motor; it built speed control model, at the same time, simulation using simulink software. It verified that the strategy of fuzzy-PID control is well than the PID control. Paper [3] using simulink simulation of control systems. Analysis of double closed loop speed regulation system of DC motor problems showed that the use of simulink simulation of the control system is feasible. In order to get better results, according to the specific parameters of electric vehicle, calculated electric vehicles power under different conditions, select larger power as a basis for selecting motor rated power to determine motor models. Base on parameters of motor, created motor model of double closed loop speed control system. The results of simulation indicate there is some limitations. On the basis of this scheme, a speed differentia about double closed loop speed regulation system of negative feedback is given. The simulation result shows the system reduced the overshoot and tended to be more stable. At the same time, the system realizes the aim of improvement of the system.

\section{THEORETICAL BASIS OF ELECTRIC VEHICLE}

\section{A. Determine of the Motor Power Rating}

When the car is moving, not only the running resistance and the driver of the car is balanced, but also the resistance power car and the engine power is always balanced[4].

Based on theory for a car, the power of the equations of equilibrium is:

$$
P_{e}=\frac{1}{\eta_{T}}\left(\frac{G f u_{a}}{3600}+\frac{G i u_{a}}{3600}+\frac{C_{D} A u_{a}^{3}}{76140}+\frac{\delta m u_{a}}{3600} \frac{d u}{d t}\right)
$$

In the formula, $P_{e}$ is power of engine; $\eta_{T}$ is the mechanical efficiency of the transmission system; $G$ is vehicle weight; $f$ is rolling resistance coefficient; $u_{a}$ is speed of car; $i$ is gradability; $C_{D}$ is air resistance coefficient; $A$ is frontal area; $\delta$ is auto rotating mass conversion coefficient; $\frac{d u}{d t}$ is accelerated speed.

When electric vehicles were driving at high speed on level pavement, ignored the slope resistance power and acceleration resistance power. At this time, the power dissipated by electric vehicles is:

$$
P_{v \max }=\frac{1}{\eta_{T}}\left(\frac{G f u_{a}}{3600}+\frac{C_{D} A u_{a}^{3}}{76140}\right)
$$

When electric vehicles were driving at a speed climbing, ignored the acceleration resistance power. At this time, the power dissipated by electric vehicles is:

$P_{i}=\frac{1}{\eta_{T}}\left(\frac{G f u_{a}}{3600}+\frac{G i u_{a}}{3600}+\frac{C_{D} A u_{a}^{3}}{76140}\right)$

According to the specific parameters of electric vehicles in table I. From formula (2) and (3) respectively is consumed by electric cars travelling at a maximum speed of power and the power consumption at a speed climbing; select a larger value, as the rated power of the motor.

The data in table 1, put quality cars, rolling resistance coefficient and the frontal area of the vehicle, and parameters of air drag coefficient into formula (2) and (3). 
TABLE I. THE PARAMETERS OF ELECTRIC CAR.

\begin{tabular}{|c|c|c|c|c|c|c|c|c|}
\hline Name & $\begin{array}{l}\text { Maximum } \\
\text { speed }\end{array}$ & Full load & $\begin{array}{c}\text { Maximum } \\
\text { gradeability }\end{array}$ & $\begin{array}{l}\text { Maximum climbing } \\
\text { speed }\end{array}$ & $\begin{array}{l}\text { Rolling resistance } \\
\text { coefficient }\end{array}$ & $\begin{array}{c}\text { Air resistance } \\
\text { coefficient }\end{array}$ & $\begin{array}{c}\text { Frontal } \\
\text { area }\end{array}$ & $\begin{array}{c}\text { Transmission } \\
\text { efficiency }\end{array}$ \\
\hline Value & $60 \mathrm{~km} / \mathrm{h}$ & $1850 \mathrm{~kg}$ & 0.1 & $15 \mathrm{~km} / \mathrm{h}$ & 0.005 & 0.49 & $3.8 \mathrm{~m}^{2}$ & 0.92 \\
\hline
\end{tabular}

These are ruined in the MATLAB Command Window: Needed power for electric vehicles is $8.67 \mathrm{kw}$.

According to the calculation results at given parameters, considering the DC may be overloaded. This paper takes power of motor which is $10 \mathrm{~kW}$ as study object.
III. THE MODEL OF SPEED REGULATION SYSTEM RECTIFIER TRIGGERING DEVICE

A. Mathematical Modeling of Double Closed-Loop DC Speed-Regulating System

Based on the above calculations, the motor rated power is $10 \mathrm{~kW}$. The basic parameters of the motor as shown in table II.

TABLE II. THE BASIC PARAMETERS OF DC MOTOR.

\begin{tabular}{|c|c|c|c|c|c|c|c|c|c|c|}
\hline Name & $\begin{array}{c}\text { Rated } \\
\text { voltage } \\
U_{a}\end{array}$ & $\begin{array}{c}\text { Rated } \\
\text { power: } \\
\boldsymbol{P}\end{array}$ & $\begin{array}{c}\text { Rated } \\
\text { current: } \\
I_{a}\end{array}$ & $\begin{array}{c}\text { Flywheel } \\
\text { torque: } \\
G D^{2}\end{array}$ & $\begin{array}{c}\text { Rated } \\
\text { speed }: \\
n_{a}\end{array}$ & $\begin{array}{c}\text { Inductance } \\
: L\end{array}$ & $\begin{array}{c}\text { Armature } \\
\text { resistance: } \\
\boldsymbol{R}\end{array}$ & $\begin{array}{c}\text { Coefficient of } \\
\text { trigger rectifier } \\
K_{s}\end{array}$ & $\begin{array}{c}\text { Speed } \\
\text { feedback } \\
\text { coefficient : } \\
\alpha\end{array}$ & $\begin{array}{c}\text { Current } \\
\text { feedback } \\
\text { coefficient: }\end{array}$ \\
\hline Value & $120 \mathrm{~V}$ & $10 \mathrm{kw}$ & $85 \mathrm{~A}$ & 3.46 & 2000 & $180 \mathrm{mH}$ & $0.025 \Omega$ & 7.8 & 0.0068 & 0.091 \\
\hline
\end{tabular}

\section{B. Parameter Design of DC Motor}

At nominal magnetic flux motor power factor is:

$C_{e}=\frac{U_{a}-I_{a} R}{n_{a}}=0.079 \mathrm{~V} \cdot \min / r$

The motor armature circuit time constant is:

$T_{1}=\frac{L}{R}=0.72 \mathrm{~s}$

By $C_{m}=\frac{30 C_{e}}{\pi}$, motor drag coefficient can be mechanical and electrical time constant is:

$T_{m}=\frac{G D^{2} R}{375 C_{e} C_{m}}=0.011 \mathrm{~s}$

\section{Design of Current Regulator}

According to the requirement of design, the steady-state astatic, so design the current regulator into Typical I System, Current-loop control object is double inertia. Therefore the current transfer of Current Loop:

$W_{A C R}(s)=\frac{K_{i}\left(\tau_{i} s+1\right)}{\tau_{i} s}$

In the formula, $K_{i}$ is proportional coefficient of current regulator. $\tau_{i}$ is the advanced time constant of current regulator.

Rectifier triggering device of DC motor drive system can be thought of as a time delay, Works on approximately one-order inertia link, it triggers the switching frequency is $15 \mathrm{kHz}$. So the period is $T=1 / 15 \mathrm{~ms}$. Take the average lost control of three-phase bridge circuit: $T_{s}=T$. According to the theory of automatic control system design, the advanced time constant of current regulator: $\tau_{i}=T_{1}$. Filtering time constant: $T_{o i}=0.067 \mathrm{~ms}$. Small time constant of current loop with approximate treatment: $T_{i}=T_{s}+T_{o i}=0.0021 \mathrm{~s}$.

At this time, open loop gain of current regulator is:

$K_{I}=\frac{1}{2 T_{i}}=241.95 \mathrm{~s}^{-1}$

Proportional coefficient of current regulator is:

$K_{i}=K_{I} \frac{\tau_{i} R}{\beta K_{s}}=6.07$

Transfer Function of current regulator is:

$W_{A C R}(s)=\frac{6.07 \times(0.72 s+1)}{0.72 s}$

\section{Design of Speed Regulator}

Transfer Function of Speed Loop:

$W_{A S R}(s)=\frac{K_{n}\left(\tau_{n} s+1\right)}{\tau_{n} s}$

As mentioned above, $T_{i}=T_{s}+T_{o i}=0.0021 \mathrm{~s}$, Speed loop time constant: $T_{n}=2 T_{i}+T_{\text {on }}=0.024 \mathrm{~s}$, Speed regulator integral time constant: ${ }^{\tau_{n}}=h T_{n}=0.12 \mathrm{~s}$, open loop 
gain of speed loop is:

$$
K_{N}=\frac{h+1}{2 h^{2} T_{n}^{2}}=206.04 \mathrm{~s}^{-2}
$$

Proportional amplification coefficient of speed regulator:

$K_{n}=\frac{(h+1) \beta C_{e} T_{m}}{2 h \alpha R T_{n}}=11.723$

Transfer Function of current regulator is:

$$
W_{\text {ASR }}(s)=11.723 \frac{(0.12 s+1)}{0.12 s}
$$

\section{SPEED CONTROL SYSTEM SIMULATION OF RECTIFIER TRIGGERING}

\section{A. Simulation of Double Closed Loop Speed Control System}

In order to get the double closed loop speed regulation system of the unit step response curve. According to the mathematical model in the previous section, Created in the Simulink model for dynamic simulation of double closed loop speed control system, and named "dian_dong_ji”, as shown in FIGURE I.

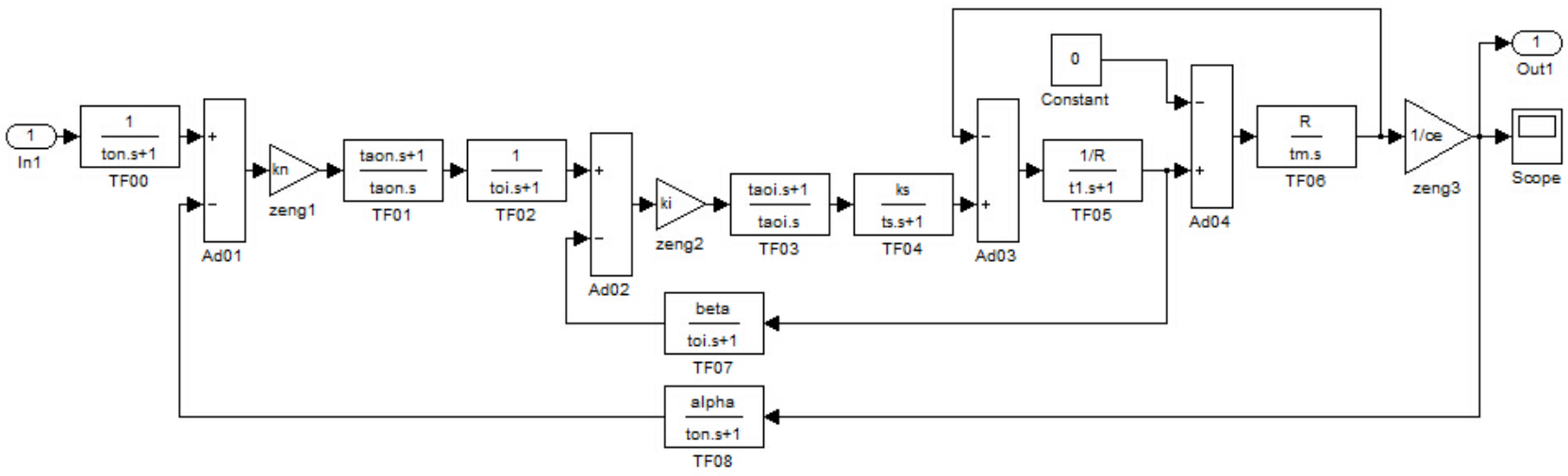

FIGURE I. SIMULATION MODEL OF DOUBLE CLOSED LOOP SPEED CONTROL SYSTEM.

Created a M-file in MATLAB, and named: function.m. Entered control parameters of the electric vehicle and DC motors. Calling MATLAB linmod () function in Simulink structure into a State space model, then called $\mathrm{tf}()$ and $\mathrm{SS}()$ function generates the system transfer function model. Calculation and analysis of the overall process is shown in FIGURE II.

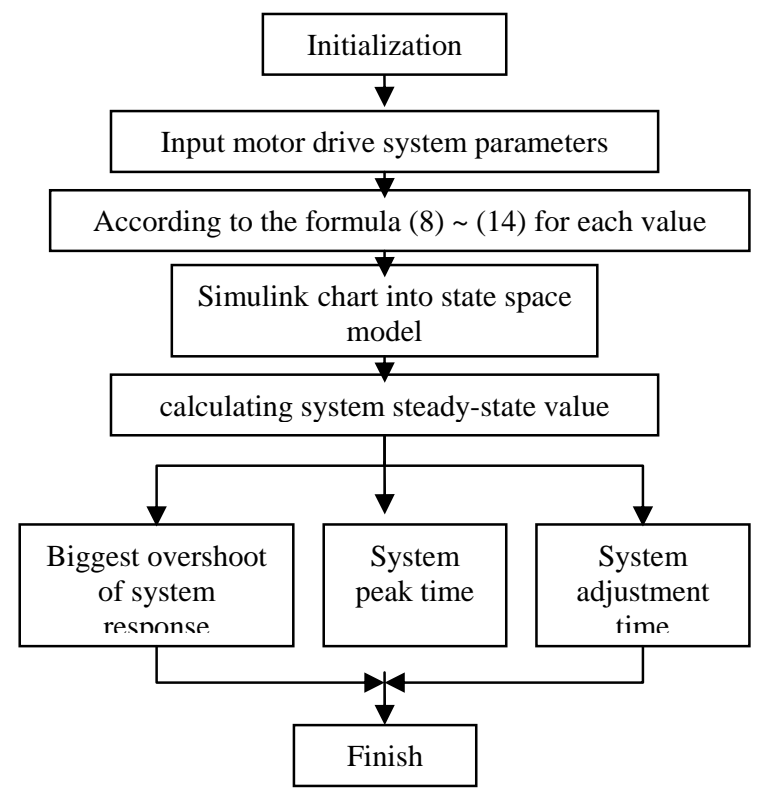

FIGURE II. THE FLOW CHART OF PROGRAM ANALYSIS.
Function.m programs ran in MATLAB window, and got the following data and Figure 6:

Program output data:

1. The biggest overshoot of system: $35.08 \%$

2. System peak time: $0.13 \mathrm{~s}$

3. System adjustment time: $0.26 \mathrm{~s}$

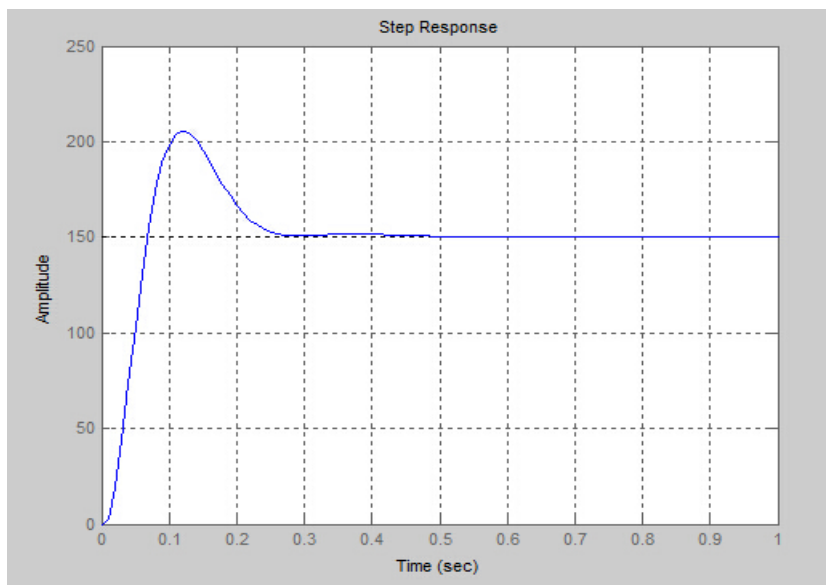

FIGURE III. DOUBLE CLOSED LOOP SPEED REGULATION SYSTEM OF THE UNIT STEP RESPONSE CURVE.

From the FIGURE II, the response curve of double closed loop speed regulation system is good; from the simulation data, the system adjustment time is $0.26 \mathrm{~s}$. But the biggest overshoot 
of system is $35.08 \%$, considering the speed stability of the system, do not satisfy the requirements of design, it should be adjusted.

\section{B. Speed Differential Feedback Simulation of Double Closed Loop Speed Regulation System}

In order to make the speed system performance and stability, satisfy the requirements of design. Based on the original systems plus a speed differential of negative feedback, the transfer function is:

$$
W_{w a i}(s)=\frac{\alpha \tau_{w a i} s}{T_{o d n} s+1}
$$

In the formula, Speed differential filter time constant: $T_{\text {odn }}=T_{\text {on }}=0.02 \mathrm{~s}, \quad \tau_{\text {wai }} \geq T_{n} \frac{4 h+2}{h+1}=0.0885 \mathrm{~s}$, means: ${ }^{\tau_{\text {wai }}}=0.0885 \mathrm{~s}$, Improved simulation model is shown in FIGURE IV.

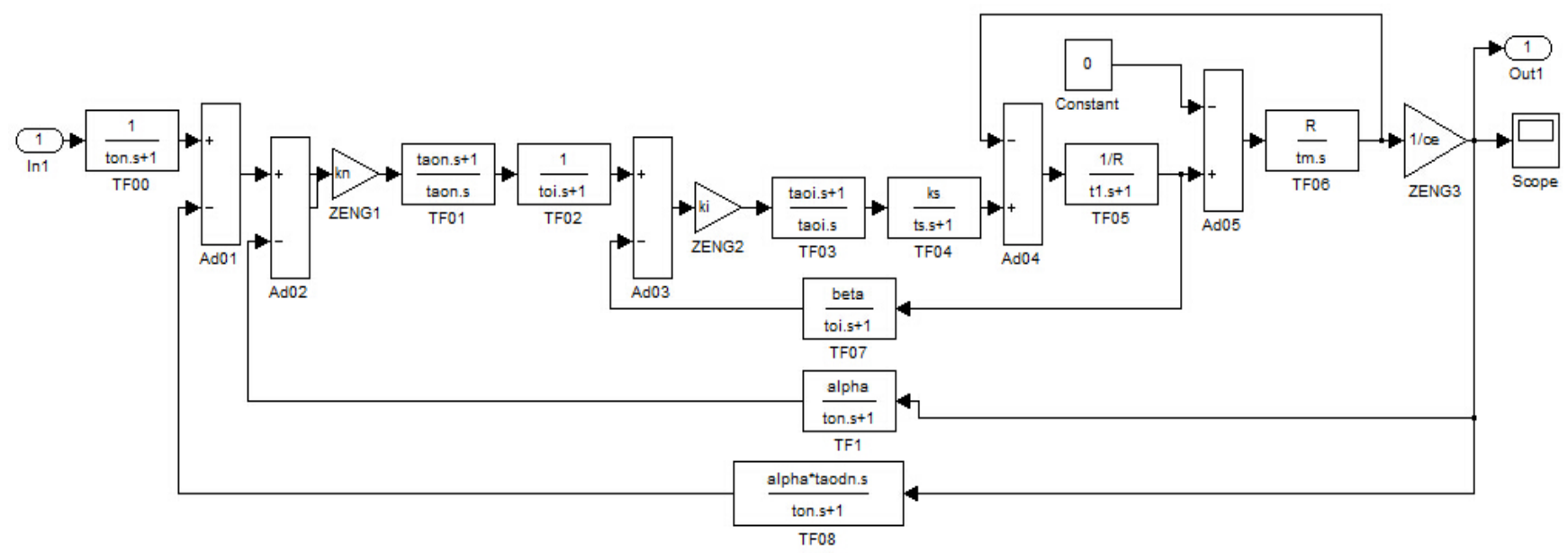

FIGURE IV. SPEED DIFFERENTIAL FEEDBACK MODEL FOR SIMULATION OF DOUBLE CLOSED LOOP SPEED REGULATION SYSTEM.

Speed differential negative feedback loop transfer function is written to the function.m program, the program ran in the MATLAB window, and produced the following data and FIGURE V.

Program output data:

1. The biggest overshoot of system: $2.71 \%$

2. System peak time: $0.36 \mathrm{~s}$

3. System adjustment time: $0.57 \mathrm{~s}$

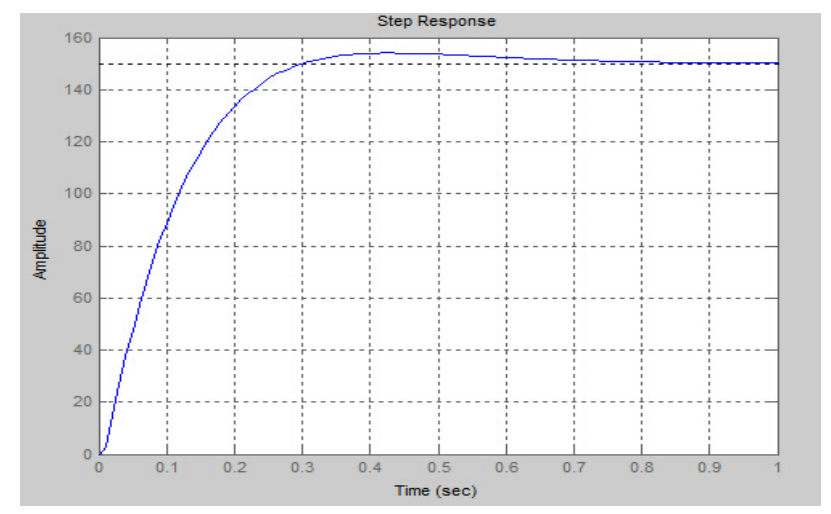

FIGURE V. SPEED DIFFERENTIAL FEEDBACK OF DOUBLE CLOSED LOOP SPEED REGULATION SYSTEM OF THE UNIT STEP RESPONSE CURVE.

It is shown from the results of simulation; the maximum overshoot of system is decreased from $35.08 \%$ to $2.71 \%$, reduced by $32.37 \%$. So the maximum overshoot of speed differential feedback double closed loop speed regulation system is improved significantly, the system get better stability and the response speed also get guaranteed. Finally the system realizes the aim of improvement.

\section{ACKNOWLEDGMENT}

1) From the simulation results of double closed loop speed control system we can see that, it is feasible to control speed using Simulink simulation, while the maximum overshoot is too large. After a speed differential negative feedback loop is taken into the original system, the system maximum overshoot is reduced by $32.37 \%$. And the overall data is improved; it is meet the project's requirements and realizes the aim of system improvement.

2) From the study of motor drive system, we can find that, modeling and simulation is not only help to enrich and develop model theory, but also it's simulation methods and results have more practical engineering application value for the development of electric vehicles, precision and other industrial manufacturing.

\section{REFERENCES}

[1] Zhou Jinlong. Study on the dynamic control of DC motor[D].Chongqing:Southest university,2008.

[2] Li Yong, Ma Fei, KAZERANI Mehrdad. Research on the Control Strategy for the Traction Motor on the Test Bench of Vehicular Energy Storage System[J]. Proceeding of the CSEE, 2014, 34(21)3481-3487.

[3] Hu Zhen, Wei Lina, Song Zhengxun. Study on simulation of double closed loop speed regulation system of DC motor[J].Journal of Changchun Institute of Optics and Fine Mechanics. 2000,23(2):37-39.

[4] Yu Zhisheng, Vehicle Theory[M],Beijing:China Machine Press,2009. 
[5] Li Zheng, Hu Guangda, Cui Jiarui, etal. Sliding-mode Variable Structure Control With Integral Action for Permanent Magent Synchronous Motor[J]. Proceeding of the CSEE, 2014,34(3):431-437.

[6] Jing Jing Xiong;Zhen Feng;Jiao Yu Liu. Simulation and Design of Double Close-Loop DC Motor Control System Based on Matlab[J]. Advanced Materials Research, 2012(546):248-253.

[7] Han Lu. Double closed loop speed regulation system of DC motor and SIMULINK simulation[J]. Ship \& Ocean Engineering, 2003(2):30-33.

[8] Kai Yu Yang;Rui Song;Hai Dong Wu, et al. Modeling and Simulation of BLDCM Double Closed-Loop Control System Based on Matlab[J]. Advanced Materials Research, 2014(898):878-882.

[9] Xu Ling, Yao Rongrong. Mathematical Simulation of Double Closed Loop Speed Regulation System of DC Motor[J]. Physics Examination and Testing, 2007, 25(1): 59-62. 